\title{
IS THE INTEGRATED WATER RESOURCES MANAGEMENT IMPLEMENTED IN JIU RIVER WATERS IN THE CONTEXT OF SUSTAINABLE DEVELOPMENT? THE MODELLING OF THE EVOLUTION OF THE CONCENTRATION OF HEAVY METALS
}

\author{
BARBU C.M. ${ }^{1, *}$ \\ NEGULESCU M.C. ${ }^{1}$ \\ UNGUREANU L. ${ }^{1}$ \\ BICĂ E. ${ }^{1}$ \\ BOGDĂNOIU C. ${ }^{1}$ \\ PANDELICA I. ${ }^{2}$
}

\author{
${ }^{1}$ Spiru Haret University \\ Faculty of Financial Management Accounting Craiova \\ 4 Vasile Conta Street, Craiova, Dolj, Romania \\ ${ }^{2}$ Agora University, Piaţa Tineretului Street \\ Oradea, Bihor, Romania
}

Received: 21/10/2015

Accepted: 22/12/2015

*to whom all correspondence should be addressed:

Available online: 22/04/2016

e-mail: cristina_barbu2000@yahoo.co.uk

\section{ABSTRACT}

Once the human technology develops, the study of its influence over the environment, the soil, the water, the flora and the fauna is becoming increasingly important. In communism, due to the lack of integrated management of water resources, the quality of the waters in Romania has constantly worsened. In the same time, the quality of the waters of the Jiu River has worsened. After 1990, especially after Romania's EU accession, our country was obligated to pass a rigorous environmental control which also includes legislation according to the international norms. Our work aims to analyze if the integrated management of water resources is applied to the Jiu River course and also, aims to analyze the evolution of the concentration of heavy metals in Jiu River course in the coming years using a mathematical forecasting model.

Keywords: environment, integrated water resources management, Jiu River course, pollutants, mathematical forecasting model.

\section{Introduction}

Humanity today is facing an acute shortage of water and water quality degradation. Water is one example of natural resources that goes largely unpriced today. Failure to recognize the economic nature of water, which means regarding water as a completely free, renewable resource, has contributed to inefficient allocation and to wasteful and environmentally damaging uses (Mylopoulos and Mylopoulos, 1999). The water resources around the world are under increasing pressure due to the rapid population and economic growth (Kourgialas et al., 2015). Water is a vital factor for man and society, therefore achieving sustainable development relies heavily on integrated water resources management. The concept of integrated water resources management (IWRM) is not a new one (Biswas, 2004), having existed for the past 60 years. He further described how some professionals of the water industry realized during the 1980 s that the situation was not as good as it seemed. In the 1990s, the feeling grew more intense as many water professionals understood that the issues regarding water were multi-dimensional, multisectoral and multi-regional, and around them developed multiple interests, agendas and causes. It was considered that these issues could only be solved with the reconciliation and coordination between 
institutions and stakeholders. Today, the question that arises is not if this kind of process is to be desired, but how it can be carried out time-and cost-efficient in the present world.

Global Water Partnership (GWP), in 2001, defined the concept of integrated water resources management as a process which aims at coordinating water, land, and other related resources in order to boost the social and economic wellbeing that results from them equitably, without affecting the sustainability of vital eco-systems. The three principles of the Integrated Resource Management (Mitchell, 1990): coordination, the participation of the stakeholders and different decision-making levels, at which the integrated resource management is to be achieved.

Water is used in most process industries. The processes using water today are being subjected to increasingly stringent environmental regulations on effluents and there is growing demand for pure water. These changes have increased the need for better water management and wastewater minimization.

The past thirty years of conferences and summits have had an essential importance for raising the awareness of the international community on the pressure of the issue of integrated water management (Rahaman and Varis, 2005). Sensible water management is considered an appropriate way to enhance life quality. The results of thirty years of conferences have been multiple commitments to IWRM, but these have rarely been put into practice. IWRM is currently a trendy concept; however, there are still problems that need to be solved, such as reducing the distance between the theoretical approach of the matter and practical implementation. Moreover, the integration and reconciliation of different sectors that are water management -related is still considered extremely challenging. In addition, the issues and solutions related to the implementation of IWRM may differ from a region to another. Therefore, universal norms, policies and guidelines for this implementation may be ineffective. The seven principles to be applied in order to successfully implement a IWRM (Rahaman and Varis, 2005): (1) Privatization, (2) Water as an Economic Good, (3) Transboundary River Basin Management, (4) Restoration and Ecology, (5) Fisheries and Aquaculture, (6) The Need to Focus on Past IWRM Experience - Integrating Lessons Learned, (7) Spiritual and Cultural Aspects of Water.

Although being a relevant concept (Van Der Zaag, 2005), IWRM is still rather elusive and fuzzy. Medema et al., (2008) critically review the claims made against IWRM and wonder if the criticism is not caused by the fact that the transition from theory to practice has raised problems (Medema et al., 2008). The authors point out that such problems have also appeared during the process of implementation for both frameworks. These discoveries are analyzed in the context of the challenge that the transition from research to practice, from science to norm raises, at a global social level.

The scientists need to create information that can be easier used, has high credibility, is legitimate and pertinent, in order to make sure that the results of research are adopted (Liu et al., 2008). When it comes to the management of dual human-water systems, the managers of water resources are often forced to deal with uncertainty and high complexity when making important decisions. Therefore, salient and legitimate scientific information is essential in order for these decisions to be well-informed.

An "unsustainable situation" means using the natural capital (defined as the total of natural resources) at a faster pace than the one these resources need in order to be restored (Holtz, 2008). The goal of environmental sustainability is to minimize these, and to halt and reverse the processes they lead to.

The environmental degradation would result in the long run in the total inability of environments to sustain human populations (Mohammad, 2011). On a global scale, this kind of degradation could imply extinction for humanity. In the short-term, environmental degradation leads to declining standards of living, the extinctions of large numbers of species, health problems in the human population, conflicts between groups fighting for a dwindling resource, water scarcity and many other major problems.

Wastewater reuse for municipal and industrial applications so far remains a whimsical game of culture, perception, religion, available technology and politics. In addition, reuse water standards are in the process of being developed in a way that will clearly take into account the local conditions while reasonably safeguarding the public health (Kellis et al., 2013). 


\section{European Programs and Measures}

After 1990, Romania adopted legislation that is in accordance with the international norms, with the purpose of managing the environment in a more rigorous manner. After 2007, the year of Romania's accession to EU, our country passes to the European legislation for water protection.

The Water Framework Directive (WFD), adopted on 23 October 2000 by the European Parliament and Council, aims primarily to establish a single coherent European framework for water policy and management, integrating the European directives in the water sector (EC, 2000). A water protection framework is set that enable the: prevention of degradation of the aquatic environment, preservation or improvement of water; promotion of the sustainable use of water based on long-term protection of available water resources; reduction or gradual elimination of the priority hazardous substances emissions into surface waters; reduction of groundwater pollution.

In order to establish a management system that is sustainable, for any water resource, it is extremely important to attain a balance between the natural biophysical system's demands and the need for social and economic development (Bakri et al., 1999). The most important question that water managers are faced with is how to reconcile the environmental objectives, which are set for the long term, with the social, political and economic demands, that are short-termed by definition. Since the social and economic activities are dependant on the biophysical resources, it is essential that the health of surface water and groundwater systems, on the long term, is the fundamental trigger for the sustainable management of water resources.

\section{The Jiu River. Presentation}

The Hydrographic area/River Basin of the Jiu River covers 16712.9 square kilometers, the length of the river network is $4954 \mathrm{~km}$ and the average density $0.29 \mathrm{~km} / \mathrm{km}^{2}$. The drought phenomenon is rather advanced on $21 \%$ of the river network.

Administrative, Jiu hydrographical area/river basin covers integral the counties: Dolj, Gorj, Mehedinti and partial the counties: Hunedoara. The present population within this zone is about 1,500 million inhabitants, from which 0,900 million inhabitants (56\%) live in the urban area (The Report of the Jiu River Basin Management Plan, 2012). From the total population, $54.84 \%$ (96.5\% in urban area, $7.5 \%$ in rural area) is connected to centralized system of water supply and $12,08 \%(21.82 \%$ in urban area, $0.005 \%$ in rural area) is connected to the waste water treatment plants.

The significant point pollution sources from the Jiu river hydrographical basin, on categories are (The Report of the Jiu River Basin Management Plan, 2012):

- Sewage: municipalities. The pollutants are, in fact, communal households from those localities and the problems caused by these ones refer to the insufficient purification of water;

- Industrial: industrial units, the mining units located along the Jiu River realizes chemical products, of which we remind urea, ammonia nitrate, nitric acid. The evacuation of sewing waters and wastewaters which are chemically impure, is made in the Jiu River, downstream from Craiova city (through the collector canal), after these pass the purification station.

- Agricultural: farms which occupies itself with breeding and industrializing pigs, evacuates wastewaters in the Jiu River.

- Accidental. In the category of other types of entropic pressures, the most important are the ones due to accidental pollution. Generally, these pollution sources are the unities which use, produce, stock up and evacuate substances that can accidentally reach the water resources, directly or with the evacuated impure waste waters. Of the pollution sources, there are reminded the thermal power stations, which due to the inadequate exploitation of the levigation ponds for slag and ashes, could lead to accidental pollution.

The domestic pollution is dependent on the number of people from the inhabited areas. The overcharge 
with organic and mineral pollutants of the domestic liquid residues is extremely big, reaching $10 \mathrm{I}$ mud/ inhabitant/ day, or $50 \mathrm{~kg}$ of solid dry matter/ inhabitant/ year (WHO, 2007).

\section{Results and discussion}

A study done by Barbu and Negulescu, (2011), shows that during 2000-2008, the pollution of water, air, soil and subsoil in the South-western area of Oltenia grew due to the intensification of economic activities (Barbu and Negulescu M.C., 2011). Barbu and Negulescu carried out a measurement on the Jiu River, at Malu Mare harvesting point, in order to establish the levels of heavy metals in these waters. This harvesting point represents the place where wastewaters from Craiova City, the largest city crossed by the Jiu River, are discharged. The heavy metals that were taken into consideration were: Zinc, Arsenic, Mercury, Lead and Nickel (figure 1). The authors pointed out that, generally speaking, the level of pollution with heavy metals was reduced between 2005 and 2007 and decreased even more in 2009 and 2010. The level of Zinc and Nickel decreased massively in 2010, compared to 2009. These two metals have great utility in the industrial sector. This reduction of the levels of Zinc and Nickel are caused by the contraction of the economic activities in the cities that are crossed by the Jiu River, namely, the city of Craiova. Pollution with heavy metals is still existent, but it is caused by waste dumps. The measurements were carried out with the use of mass spectrometry with inductively coupled plasma in $\mu \mathrm{g} \mathrm{I}^{-1}$. The highest concentration of nickel admitted in Romania is $\mathrm{Ni}=2,1 \mu \mathrm{g} \mathrm{I}^{-1}$ and the highest concentration of zinc

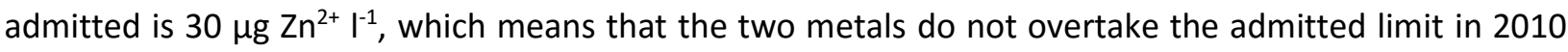
(Ministry of Waters and Environmental Protection, Order No. 1146 of 12/10/2002).

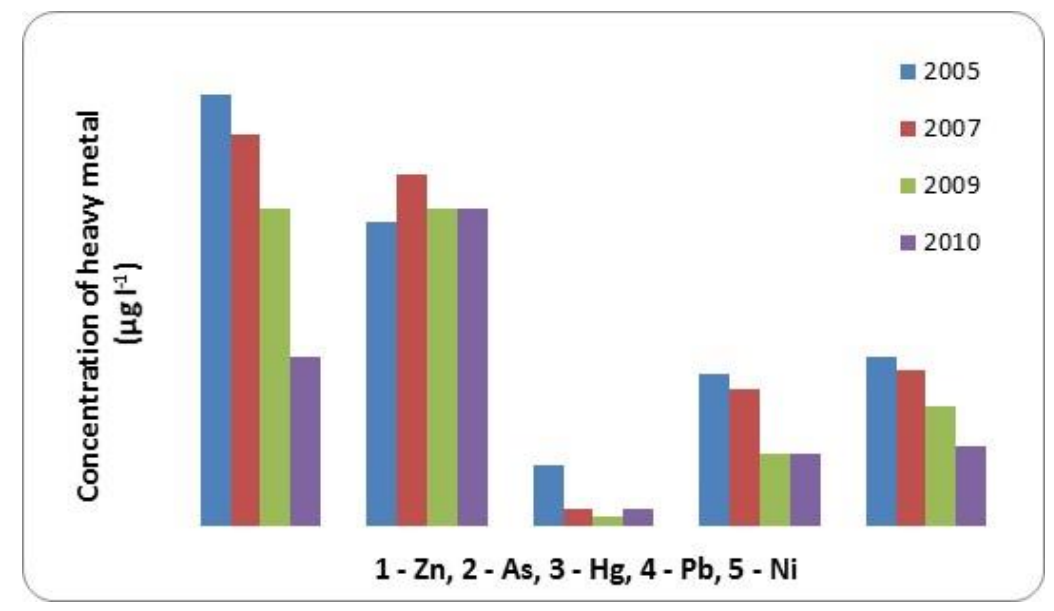

Figure 1. The level of heavy metals in Jiu River (Barbu and Negulescu, 2011)

In 2015 the samples have been taken in July, from six different points of the Jiu River. These points were: (1) Campu' lui Neag (The West Jiu); (2) Lupeni (The West Jiu); (3) Livezeni (The East Jiu); (4) Podari; (5) Malu Mare and (6) Zaval, the point where the Jiu River flows into the Danube (see Figure 2). The samples were collected and analyzed by the study authors using mass spectrometry with inductively coupled plasma. The measured data in 2013 shows that the zinc and nickel increased in Malu Mare harvesting point compared to 2010, which shows on the one hand economic activity grew in the city crossed by Jiu. On the other hand, the increase in concentration of metals shows that wastewater treatment plants have not been improved and metal waste is directly discharges in Jiu. Nickel concentration increases even slightly over the admitted limit.

Bringing together the two graphs (figure 3), it can be observed that in 2010, the Malu Mare point registered the lowest values. The decrease in these values is a consequence of the reduced economic activity during the crisis. After 2010, the recorded values start rising, thus proving that the economic activity has been increasing. 


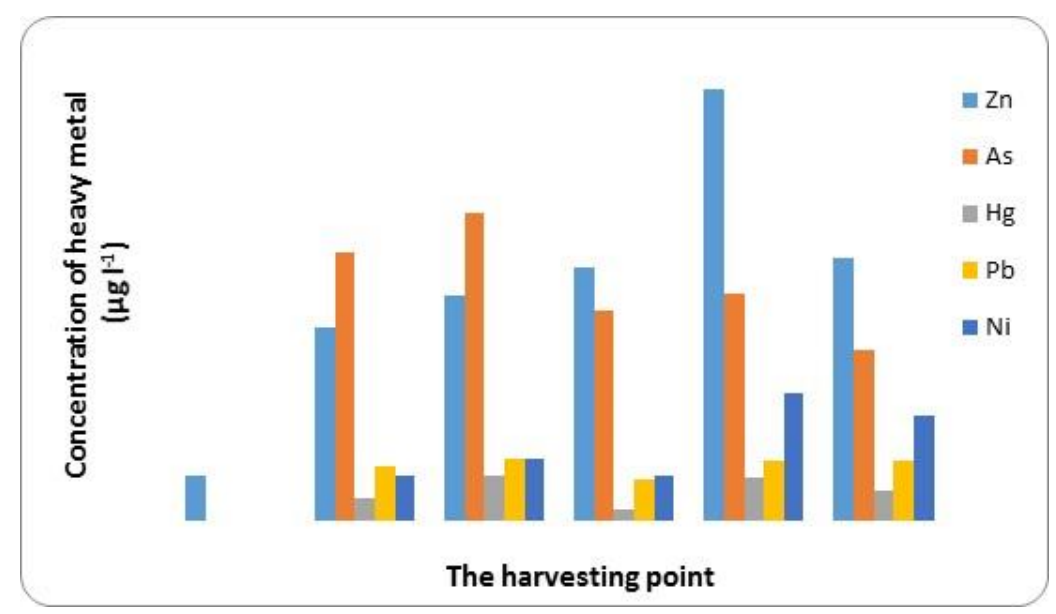

Figure 2. The level of heavy metals in Jiu River in 2015

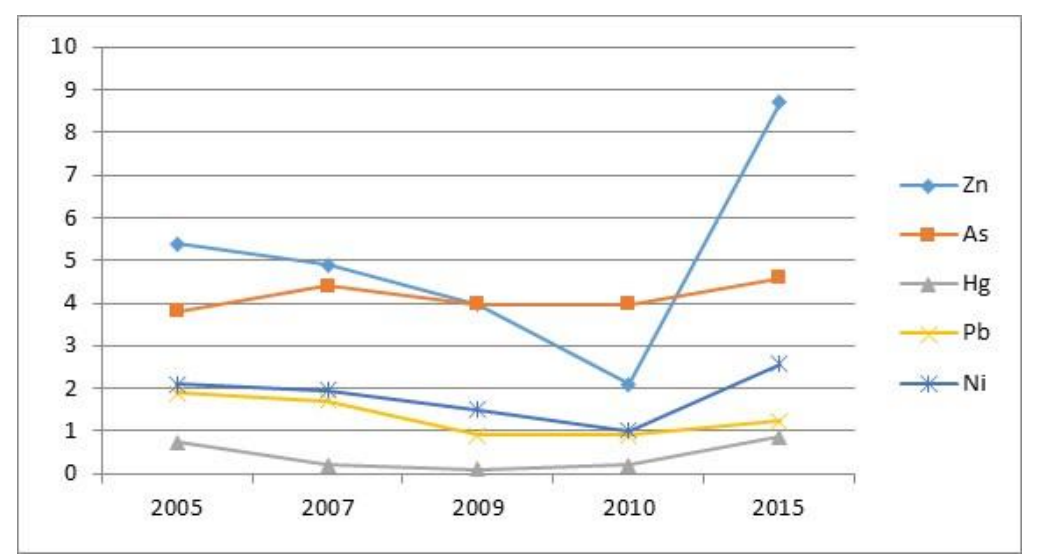

Figure 3. The evolution of heavy metal concentrations in Malu Mare point

From the data collected so far it can be seen that the spreading cloud of pollutants at the Malu Mare point can be indicated by a parabolic function that accepts a minimum point, ie, a function of the form: $y=a+b t+c t^{2}$ that has the following graph:
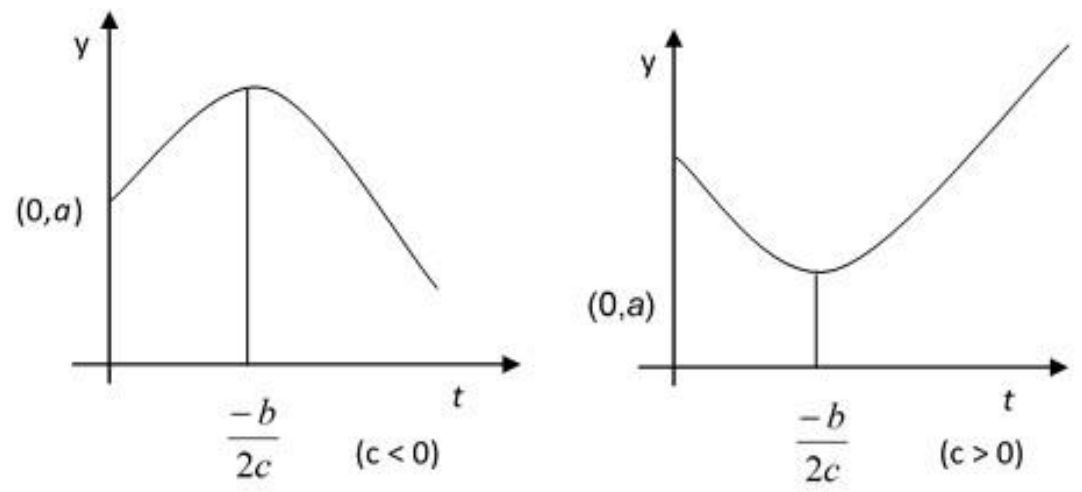

Figure 4. The function graph

The equations system for calculating the constants $a, b, c$ : 


$$
\left\{\begin{array}{l}
n \cdot a+\left(\sum t\right) b+\left(\sum t^{2}\right) c=\sum y \\
\left(\sum t\right) a+\left(\sum t^{2}\right) b+\left(\sum t^{3}\right) c=\sum t y \\
\left(\sum t^{2}\right) a+\left(\sum t^{3}\right) b+\left(\sum t^{4}\right) c=\sum t^{2} y
\end{array}\right.
$$

The $a, b, c$ parameters result from the ratio of the following determinants:
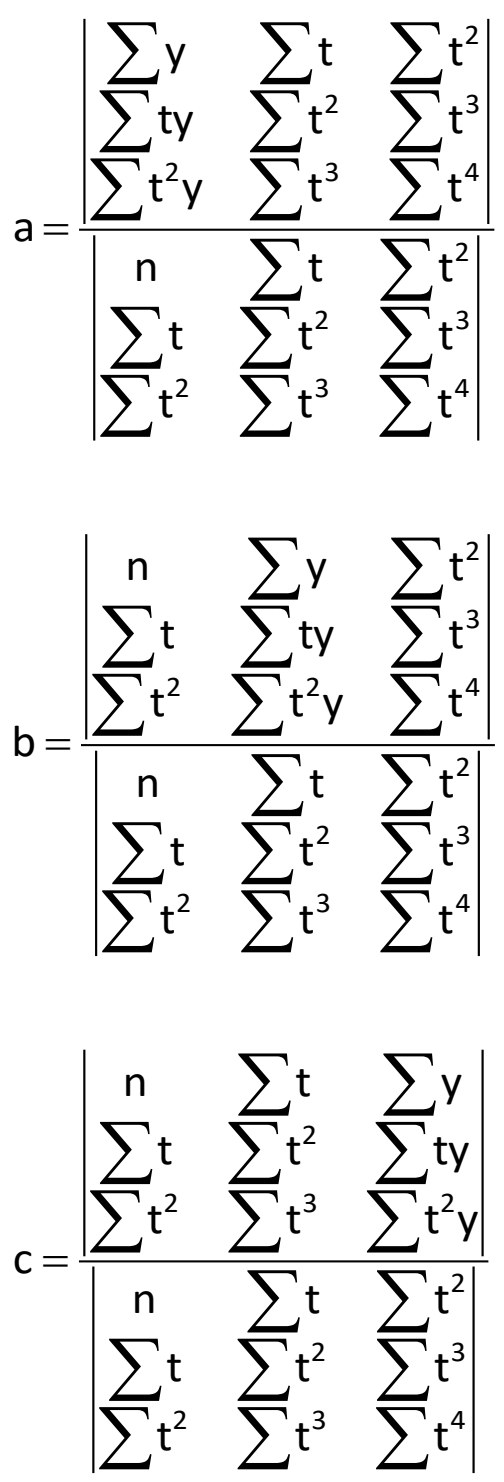

In the $\mathrm{Zn}$ situation, in order to determine these parameters, we will use data from the table below:

Table 1. The evolution of Zn concentration, în Malu Mare point, from 2003 to 2015

\begin{tabular}{ccccc}
\hline Year & $\mathbf{t}$ & $\mathbf{y}$ & $\mathbf{t y}$ & $\mathbf{t}^{\mathbf{2}} \mathbf{y}$ \\
\hline $\mathbf{2 0 0 3}$ & -3 & 5,7 & $-17,1$ & 51,3 \\
\hline $\mathbf{2 0 0 5}$ & -2 & 5,4 & $-10,8$ & 21,6 \\
\hline $\mathbf{2 0 0 7}$ & -1 & 4,9 & $-4,9$ & 4,9 \\
\hline $\mathbf{2 0 0 9}$ & 0 & 3,97 & 0 & 0 \\
\hline $\mathbf{2 0 1 1}$ & 1 & 2,1 & 2,1 & 2,1 \\
\hline $\mathbf{2 0 1 3}$ & 2 & 3,5 & 7 & 28 \\
\hline $\mathbf{2 0 1 5}$ & 3 & 8,7 & 26,1 & 78,3 \\
\hline Sum & 0 & 34,27 & 2,8 & 186,2
\end{tabular}

By replacing them in the formulas, we obtain the linear system, with the following solutions: $a=3,9$; 
$b=-0,1 ; c=0,5$

The resulting function is:

$F(t)=0,5 t^{2}-0,1 t+3,9$

Where the year 2016 is $t=4$ and $f(4)=11,5$ - the forecasted value for 2016 .

Using this function, for the year 2017, we find the value $f(5)=15,9$.

\section{Conclusions}

Even at present Oltenia faces problems of environmental and infrastructure.

Human agglomerations do not have sewage collection systems or appropriate collection and disposal of sludge systems from the treatment plants. This leads to increased pollution in Malu Mare area, the point where wastewaters from Craiova City, are discharged. Also the municipalities having inconsistent waste deposits. The Jiu River is so polluted with plastics, glass, paper, heavy metals, oils, detergents, etc. The agrozootechnical farms do not have proper storage / use of manure, the municipalities are vulnerable points to nitrate pollution from agricultural sources areas, the units use pesticides and do not comply the law in effect, and all these agricultural activities can lead to significant diffuse emissions.

On the river Jiu there are deposits of raw materials, finished products, auxiliary products, inconsistent waste storage units that produce diffuse accidental pollution, abandoned industrial sites. This leads to an increase in pollution with heavy metals throughout the river Jiu.

Spring of 2015 has been very rainy. Heavy rains and floodwaters of the Jiu river wash the waste dumps dissolving the active substances found in minerals ( $\mathrm{Fe}, \mathrm{Cu}, \mathrm{Zn}, \mathrm{As}$, etc.) or in active and deserted galleries. The summer of 2015 has been extremely dry. Drought as well as industrial pollution and uncontrolled waste disposal on shore or river bottoms leads to the reduction of surface water purity. Specifically, because of the drought, the underground water level is diminishing and that of the pollutants remains unchanged.

Heavy rains, floods caused by deforestation drain the mine water as well contributing to increased concentrations of heavy metals in the Jiu waters.

Regarding water resources, a major problem of mankind is to find practical ways to manage water resources available to sustain future populations, with a good standard of living, without degrading the natural systems and their ability to sustain the world's population on an undefined future. This requires drastic changes in the current standards for evaluating new projects, and the radical measures for reconstructing the design and operation of water management systems.

Pollution has been less fought in 2012. Pollution caused by agriculture, energy, mining, industry and transportation is still high. And an important quantity of industrial wastewater that contains chromium, mercury, lead, zinc, and other toxins, is still discharged on a regular basis - without being treated - into coastal waters and rivers.

Punctually, the study's findings are: Collection of waste from the public shall be selective; they end up on landfills as such, blended, thus losing a large portion of their potential useful (paper, glass, metals, plastic materials); The deposits are sometimes located close to surface water or groundwater; Landfills are not properly equipped for the protection of the environment, leading to water pollution and soil in these areas; The deposits, especially those towns, are not operated properly; There is no a strict control of quality and quantity of the waste; There is no a strict control of quality and the quantity of pesticides used in agriculture; Land occupied by landfills, especially land occupied by dumps of sterile are considered degraded lands, which can no longer be used for agricultural purposes; at the present time in Romania, over 12000 hectares of land are affected by domestic and industrial waste storage;

All the discussion above, it is concluded that on the Jiu River, is not applied an integrated management system. 
Given this conclusion, following the calculated forecast, in 2016, 2017 etc, the concentration of heavy metals in Malu Mare point will increase.

\section{References}

Bakri D.Al, Wickham J. and Chowdhury M. (1999), Biophysical demand and sustainable water resources management: an Australian perspective, Hydrological Sciences Journal, 44(4), 517-528.

Barbu C.M. and Negulescu M.C. (2011), Does the economic crisis affect oltenia's environment (II)?, Journal of Applied Economic Sciences, VI3(17), 205-206.

Biswas A.K. (2004), Integrated Water Resources Management: A Reassessment, Water International, 29(2), 248-256.

Directive 2000/60/EC of the European Parliament and of the Council of 23 October 2000 establishing a framework for Community action in the field of water policy, available at http://ec.europa.eu/environment/water/waterframework/index en.html

Holtz C. (2008), Global Health Care, Issues and Policies. Jones and Bartlett Publishers, Canada.

Kellis M., Kalavrouziotis I.K. and Gikas P. (2013), Review of wastewater reuse in the Mediterranean countries, focusing on regulations and policies for municipal and industrial applications, Global NEST Journal, 15(3), 333-350.

Kourgialas N.N., Karatzas G.P. and Morianou G. (2015), Water management plan for olive orchards in a semimountainous area of Crete, Greece, Global NEST Journal, 17(1), 72-81.

Liu H., Gupta H., Springerb E. and Wagenerc T. (2008), Linking science with environmental decision making: Experiences from an integrated modeling approach to supporting sustainable water resources management, Environmental Modelling \& Software, 23(7), 846-858.

Medema W., Mcintosh B.S. and Jeffrey P.J. (2008), From Premise to Practice: a Critical Assessment of Integrated Water Resources Management and Adaptive Management Approaches in the Water Sector, Ecology \& Society, 13(2), 29-43.

Ministry of Waters and Environmental Protection) Order No. 1146 of 12/10/2002. Approval of the Norms regarding reference objectives for surface water quality classification.

Mitchell B. (1990), Integrated water management: international experiences and perspectives, London: Belhaven Press.

Mohammad N. (2011), Environment and sustainable development in Bangladesh, International Journal of Law and Management, 53(2), 89-107.

Mylopoulos Y.A. and Mylopoulos N.A. (1999), Economic incentives in sustainable water management: i risk - based decision analysis approach for determining groundwater pollution charges under uncertainty, Global Nest: the International Journal, 1(3), 205-215.

Rahaman M.M. and Varis O. (2005), Integrated water resources management: evolution, prospects and future challenges, Science, Practice, \& Policy, 1(1), 15-21.

The Report of the Jiu River Basin Management Plan, (2012), available at http://www.defileuljiului.ro/index.php/apndj/constituire/regulament.

Van Der Zaag P. (2005), Integrated Water Resources Management: Relevant concept or irrelevant buzzword? A capacity building and research agenda for Southern Africa Physics and Chemistry of Earth, 30(11-16), 867-871.

World Health Organization - Annual Report of WHO (2007), available at http://www.who.int/whr/2007/chapter1/en 